\title{
STUDENT OUTCOME PORTFOLIOS FOR THE COURSE \& PROGRAM ASSESSMENT
}

\author{
Swami Karunamoorthy \\ Saint Louis University, St. Louis, Missouri
}

\begin{abstract}
Assessment is not a new phenomenon in engineering profession; however it is a new paradigm in engineering education. Traditionally, the instructor evaluates the student's performance by quizzes and tests that can be classified as open loop assessment. The assessment methods with a feedback closed loop remains as a challenge to both faculty and administration. An emphasis is given in this paper to use the student outcome portfolios as a measurement tool for the closed loop assessment process. It gives a new perspective to the exhibit materials for the purpose of accreditation.
\end{abstract}

\section{Introduction}

In most of the classroom education, the instructor delivers a brilliant lecture to his/her satisfaction. However, an effective teacher would like to know how much of the knowledge has been absorbed or learned by the students from the lecture. While learning is proportional to instruction, the essential link between them is assessment. The process of instruction involves continuous decision making by an instructor. The instructor decides what to teach, how to teach, how much to teach, how long to teach, what to review, what to ask in the test, and how to evaluate the test. These decisions would be effective only when the instructor has information about students' learning through assessment. Then, the instructor can match his decisions based on the feedback from assessment. It would naturally happen only when an instructor appreciate and believe in the assessment process. In order to do that he/she should have a good understanding of what is an assessment and how it can be used to improve the pedagogical process.

\section{Assessment}

One of the definitions available for assessment in the literature ${ }^{1}$ : "Assessment is the process of collecting, synthesizing, and interpreting information to aid in decision making". Another perspective is that the instructor is aware or mindful about students' learning during the pedagogical process. So the assessment can be defined as a phenomenon that would facilitate Mindful Instruction in engineering education.

Assessment shifts the focus of instruction from teaching to learning. It is a paradigm shift in the pedagogical process. It facilitates to inform and improve the instruction. It requires the instructor to believe that all students can learn and to 
accommodate individual differences in students' learning styles. Instructional intervention with a feedback through assessment promotes student's understanding of the lecture or absorbing the knowledge. The lights go on with students to indicate that learning has occurred and the instruction is effective. A good feedback mechanism requires the understanding of various components, or the embodiment of assessment system.

\section{Embodiment of Assessment System}

The various components of the Assessment System can be identified as follows: (1) Objectives, (2) Outcomes, (3) Process, and (4) Feedback. For effective assessment, the objectives should be measurable, the outcomes should be demonstrable, the process should be quantifiable, and the feedback should be feasible for implementation. It can be performed at course level as well as program level. The course level assessment improves the quality of a course while the program level assessment provides continuous quality improvement of the whole program.

\section{Objectives:}

Learning Objectives should be established for each course and the program as a whole. The objectives can be generated by answering the question, what every student is expected to accomplish in terms of knowledge, values, and skill at the end of a particular course or program. These objectives should be comprehensive, measurable, and flexible and they need to be systematically reviewed and updated. Establishing objectives help to communicate expectations to students. Also it helps the instructor to focus on meeting those objectives.

\section{Outcomes:}

Demonstrable Learning Outcomes should be established for each course as well as the complete program. The outcomes should be tied to the objectives and they can be generated by answering the question, what every student is expected to demonstrate a specified knowledge, value, or skill at the end of a particular course or program. One could easily form a matrix of objectives and outcomes in order to identify the link between each outcome to a corresponding objective. The products required to evaluate the outcome can be generated by answering the question, what evidence is needed to demonstrate a particular outcome.

\section{Process:}

The process should be quantitatively understood and controlled. Quantifiable method of measurement should be established as a tool for assessment. The degree to which a particular outcome or objective is possessed or demonstrated by an individual can be differentiated by assigning different numbers. The methods for collecting information can be classified as Selected-response method and Constructed-response method $^{2}$. The selected-response method requires a student to choose a response from those provided. These methods may include multiple-choice, true-false, structured 
interview, and surveys. In a constructed-response method, the students construct a response rather than choosing a response. Examples for this method may include sentence completion, short answer, essay, unstructured interview (focus group discussion), papers and reports. Evaluation of these responses can be interpreted based on criterion based assessment or norm based assessment. In the case of criterion based assessment, the students' performance is compared with a designated standard level of performance. In norm based assessment, the students are compared with each other or with some other group of students. However, this approach does not indicate the actual level of knowledge or understanding.

\section{Feedback:}

The results from Process component of the assessment can be used as feedback to make decisions about students, instruction, curriculum, instructors, and program. They should be feasible for implementation to improve the outcomes as well as the processes. For example, the classroom assessment has two important feedback. One of them is to inform the instructor about students' level of understanding and to indicate the roadblocks in learning process so that appropriate instructional interventions can be planned. The other one is to inform students, parents, and others about student outcome. In program level the results of the assessment can be used as feedback to continuously improve the quality of program.

\section{Student Outcome Portfolios}

Student outcome portfolio is a viable measuring tool for assessment process and it can be used at course level as well as program level as shown in Figure 1. In course level, the outcome assessment of course-portfolio provides a feedback for an improvement of the quality of a course. A course-portfolio may include but not limited to course outline with course objectives and outcomes, syllabus, grading scale, coursepolicy, homework, quizzes, tests, design exercise (or project reports), computer assignments, and any other evaluation or assessment materials. The portfolio can be evaluated to verify for satisfying the course objectives and any other program outcomes that would be appropriate for the course. A matrix of objectives versus outcomes can be generated to facilitate the assessment. Any weakness or deficiency or concern observed in this process can be used as feedback to improve the quality of the course.

In program level, assessment of the program outcome-portfolio provides a feedback for continuous quality improvement of the program. The program outcome portfolios may include one portfolio for each designated outcome. The number of outcomes should be a minimum of eleven ${ }^{3}$, from (a) through $(\mathrm{k})$ as defined in the guidelines of Accreditation Board for Engineering and Technology (ABET). There may be more outcomes defined based on the need of a program and its constituency. Each portfolio should contain evidence materials collected from freshmen through senior year to demonstrate the specified outcome. The results from this assessment provide a measure of the accomplishment or the degree of accomplishment of a particular outcome. Also, it indicates how well a particular outcome is integrated in the curriculum from 
freshmen through senior year. Any deficiency, weakness or concern observed in this process can be used as feedback to improve the quality of the program.

In addition to improving the quality of a course as well as a program, the student outcome-portfolios are valuable exhibit materials for accreditation. Traditionally, the course portfolios are exhibited during an accreditation visit by ABET. The program evaluator has to walk through the maze of all the course portfolios to verify whether all program outcomes are satisfied and how well they are integrated through the curriculum. It is not only cumbersome to the program evaluator and it is equally difficult for a faculty member to explain in the case of any discrepancy. The program outcome portfolio alleviates this confusion and provides a better exhibit of a particular outcome with materials separated by the dividers of Freshmen year, Sophomore year, Junior year, and Senior year. These portfolios would facilitate an effective and efficient accreditation process.

\section{Objectives and Outcomes}

The feedback for measurable objectives and demonstrable outcomes for a course as well as a program is given in Figure 2. The program objectives and outcomes should be developed based on the input from constituencies (Students, Alumni, Faculty, and Employer - SAFE) and Industrial Advisory Committee. Periodic review and modification of program objectives and outcomes would facilitate the quality of a program. In course level, each course should have the objectives and outcomes that are consistent with program objectives and outcomes. During the course, the instructor should periodically assess the students' learning and use the feedback for appropriate instructional intervention to enhance the learning process. Minute paper $^{4}$, concept quiz, quiz on pre-requisite knowledge, problem workshop (group learning) ${ }^{5}$, and any other innovate techniques can be used to assess students' learning ${ }^{6}$. At the end of a course, each student should complete a course assessment survey. The survey and the concept

quiz can be administered manually or through web based tools ${ }^{7}$. Also the instructor should complete a separate survey for the course assessment. The feedback can be used to improve the quality of present course or to reengineer the prerequisite course.

\section{Course Assessment Survey}

A typical course outcome survey by students is given in appendix. The outcomes include the ones specified by ABET as well as some more that are appropriate for a course. The students are asked to rate each outcome into one of the five categories as Poor, Average, Good, Excellent, or Not Applicable. These ratings are quantified by assigning a number to each one of them. The rating of Poor is equal to "1" (equivalent to a letter grade D) while the rating of Average is equal to "2" (equivalent to a letter grade C). Similarly, the rating of Good is equal to "3" (equivalent to a letter grade B) while the rating of Excellent is equal to "4" (equivalent to a letter grade A). Now the results can be easily quantified and an average score for each outcome can be computed. If a particular outcome has the score of below average, it can be improved with an appropriate change in pedagogical methods. 
The course assessment by faculty is also given in appendix. It provides an opportunity for an instructor to reflect upon his/her pedagogical methods and assessment techniques. This survey includes (a) a list of course objectives, (b) pedagogical methods, (c) assessment methods, (d) inquiry questions, and (e) suggestions. The results from this survey would be a valuable feedback to the instructor when he teaches the course again. Also, it can be used by another instructor who may teach the same course later or to the person who teaches the prerequisite course. All these surveys can be discussed collectively in a faculty retreat at the end of each semester. It would benefit the entire faculty in the department and would help them to share the information in good faith.

\section{Conclusions}

For Mindful-Instruction, assessment with feedback loop is not only necessary but also essential. Student outcome portfolios are viable tools for assessment process and the feedback from this process can be used to improve the quality of a course as well as a program. Also, they serve as effective exhibit materials for the program evaluator during ABET accreditation visit. The students' learning assessment during the course is an efficient method for instructional intervention for the proliferation of learning process. The course-assessment survey by students at the end of the course provides a quantified feedback that can be used to improve the quality of the course. The course-assessment surveys by faculty complement the students' survey and serve as feedback for improving the pedagogical methods to enhance the students' learning.

\section{Bibliography}

1. Airasian P.W., "Classroom Assessment", McGraw-Hill Publishers, 1997.

2. McMillan J.H., "Essential Assessment Concepts for Teachers and Administrators", Corwin Press Inc., 2001.

3. "Criteria for Accrediting Engineering Programs", EAC-ABET, 2000.

4. Angelo T.A. and Cross K.P., "Classroom Assessment Techniques, A Handbook for College Teachers", Jossey-Bass Publishers, 1993.

5. Karunamoorthy S., "Problem Workshop - A Viable Concept for Design Integration", ASEE Annual Conference Proceedings, 1994.

6. Shaeiwitz J.A., "Classroom Assessment", Journal of Engineering Education, April 1998.

7. Karunamoorthy S. and Olliges R.H., "Web Technology in Engineering Education - How and Why", ASEE Annual Conference Proceedings, 2000. 


\section{Biographical Information}

Dr. Swami Karunamoorthy is the Associate Dean for Engineering at Parks College of Engineering \& Aviation, Saint Louis University. He is also a professor of Aerospace and Mechanical Engineering. He has several publications in the areas of Aerospace Engineering, Mechanical Engineering and Engineering Education. He is the Vice President for Mid-West region of the American Helicopter Society and an active member of the ASEE, AIAA, and ASME.

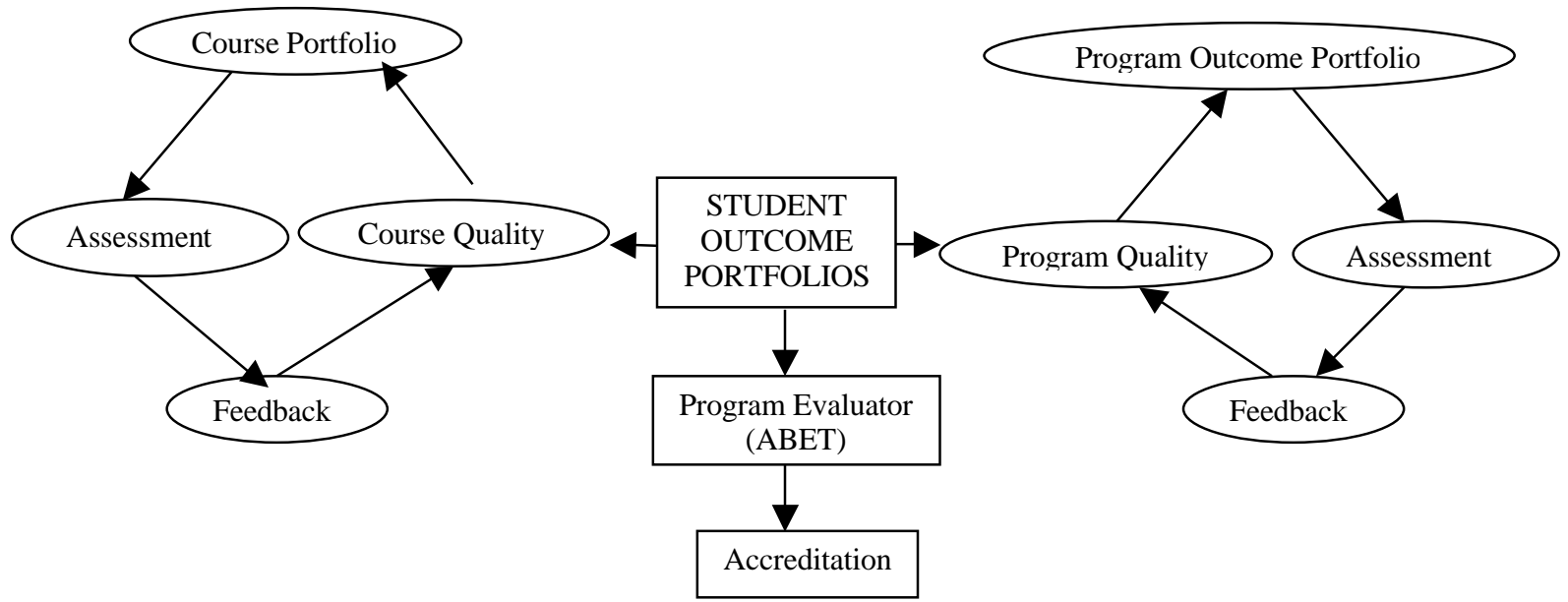

Figure 1. Student Outcome Portfolios

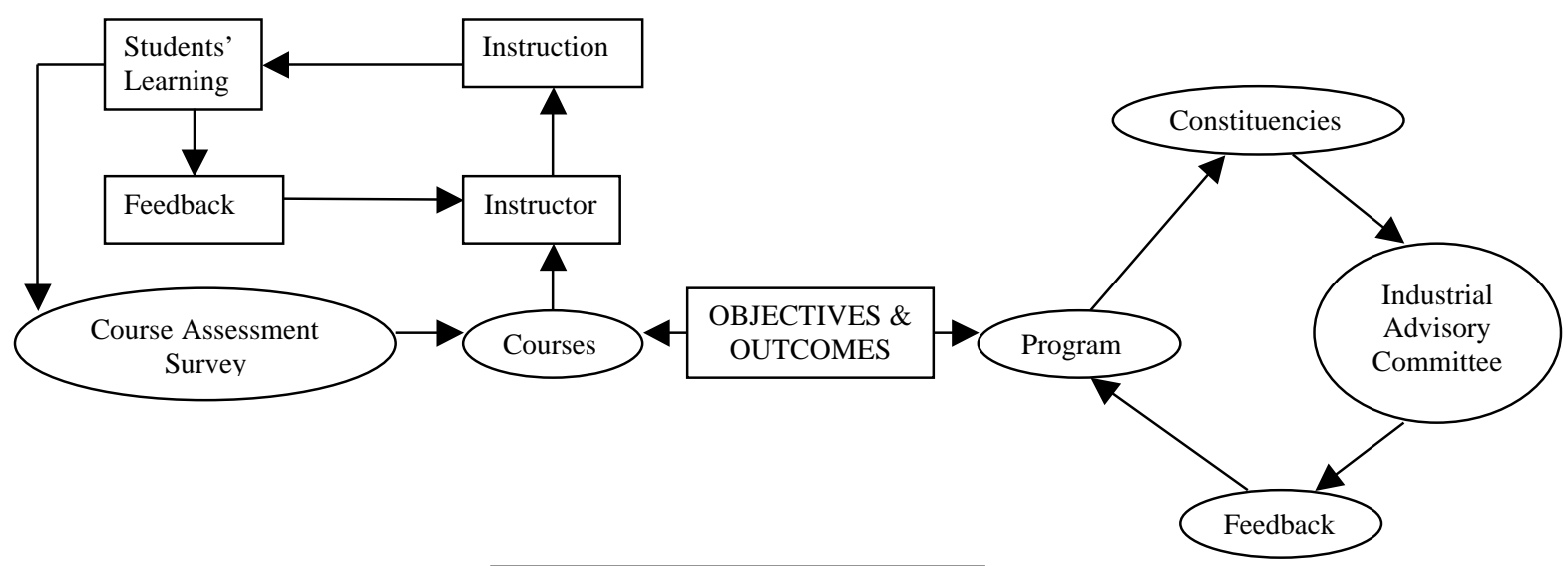

Figure 2. Objectives and Outcomes 


\section{Appendix}

\section{COURSE ASSESSMENT - STUDENT}

Please answer all the questions in this form. Your response is very important for the continuous quality improvement of this course. These responses will be treated as confidential.

Semester:

Course Number:

Course Title:

Indicate your choice by circling one of the following categories:

N/A - Not Applicable $\quad 1$ - Poor $\quad 2$ - Average 3 -Good $\quad 4$ - Excellent

1. Ability to accomplish the course objectives can be rated as,

$$
\text { N/A } 11 \quad 2 \quad 3 \quad 4
$$

2. Ability to apply mathematics, engineering and science knowledge from pre-requisite courses can be rated as,

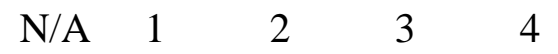

3. Ability to use statistics for the design and conducting experiments can be rated as,

$$
\text { N/A } 11 \quad 2 \quad 3 \quad 4
$$

4. Ability to use statistics for the analysis and interpretation of data can be rated as,

$$
\text { N/A } 11 \quad 2 \quad 3 \quad 4
$$

5. Ability to design a system, component, or process through the design problems and/or projects performed in this course can be rated as,

$$
\text { N/A } 11 \quad 2 \quad 3 \quad 3 \quad 4
$$

6. Ability to function on multi-disciplinary teams can be rated as,

$$
\text { N/A } 11 \quad 2 \quad 3 \quad 4
$$

7. Ability to identify, formulate, and solve engineering problems can be rated as,

$$
\text { N/A } 1142 \quad 3 \quad 4
$$

8. An exposure in this course for professional and ethical responsibility can be rated as,

$$
\text { N/A } 1123 \quad 3 \quad 4
$$

9. An exposure in this course for written and oral communication can be rated as,

$$
\text { N/A } 11 \quad 2 \quad 3 \quad 4
$$


10. An exposure in this course to understand the impact of engineering solutions in a global and societal context can be rated as,

$$
\text { N/A } 11 \quad 2 \quad 3 \quad 3 \quad 4
$$

11. An exposure in this course for life-long learning (how this course is related to the next course in sequence and/or graduate school) can be rated as,

$$
\text { N/A } 11 \quad 2 \quad 3 \quad 4
$$

12. An exposure in this course for contemporary issues (examples of current engineering problems and modern methods of engineering solutions) can be rated as,

$$
\text { N/A } 11 \quad 2 \quad 3 \quad 4
$$

13. Ability to use the techniques, skills, and modern engineering tools can be rated as,

$\begin{array}{lllll}\text { N/A } & 1 & 2 & 3 & 4\end{array}$

14. Ability to use the computers for solving engineering problems can be rated as,

$$
\text { N/A } 11 \quad 2 \quad 3 \quad 3 \quad 4
$$

15. The classroom augmentation techniques (Video, Field Trip, Lab-Demo, Guest Lecture, Web application etc.) used in this course can be rated as,

$$
\text { N/A } 11 \quad 2 \quad 3 \quad 4
$$

SUGGESTION:

How this course can be modified to improve the quality and enhance the learning process? (Write your suggestions below) 


\title{
COURSE ASSESSMENT - FACULTY
}

Please answer all the questions and include the course outline handout.

NAME:

DATE:

\section{COURSE NUMBER/TITLE:}

\section{TEXT BOOK:}

A. List the course objectives:

B. Pedagogical Methods used in this course (Please check all that apply):

\author{
Classroom Lecture \\ Laboratory Demonstration \\ Design Experience (Project/Problem) \\ Computer Application (Project/Problem) \\ Web-Based Tools \\ Guest Lecture from Industry and/or Government \\ Seminar \\ Video Presentation \\ Field Trip \\ Other (Describe)
}

C. Assessment Methods used in this course (Please check all that apply):

Homework

Quizzes

Tests

Web Based Test

Design Project Report

Computer Project Report

Oral Presentation

Other (Describe)

D. Questions: (Please answer all the questions by circling the appropriate category)

N/A - Not Applicable $\quad 1$ - Poor 2 -Average 3-Good 4 -Excellent

1. Level of satisfaction in accomplishing the course objectives can be rated as,

Comments:

$$
\text { N/A } 11 \quad 2 \quad 3 \quad 4
$$


2. The success due to the implementation of the suggested changes* from previous year assessment can be rated as,

$$
\text { N/A } 1 \quad 2 \quad 3 \quad 3 \quad 4
$$

Comments: (* List all the changes made and comment on their success or failure)

3. The average assessment of this course by the students is rated as,

Comments:

$\begin{array}{lllll}\text { N/A } & 1 & 2 & 3 & 4\end{array}$

4. The average performance of the students in the class is rated as,

Comments:

N/A $11 \quad 2 \quad 3 \quad 4$

5. Institutional facilities and resources available for effective teaching can be rated as, Comments:

N/A $11 \quad 2 \quad 3 \quad 4$

E. Suggestions:

1. Suggest some methods to improve the quality of the present course:

2. Suggest some methods to improve the quality of the pre-requisite (if any) course:

3. Any other general suggestions to enhance the learning process in this course: 